\title{
IMPORTÂNCIA ATRIBUÍDA AO ENSINO SUPERIOR POR ESTUDANTES DO ENSINO MÉDIO DE PONTAL DO PARANÁ
}

\author{
Matheus Kopp Prandini - matheus10696@gmail.com \\ Universidade Federal do Paraná \\ Alan D’Oliveira Correa - alanufpr2016@ gmail.com \\ Universidade Federal do Paraná
}

Mirelly Lacerda Pinheiro- mirelly.lacerda.pinheiro@ gmail.com

Universidade Federal do Paraná

Vinicius Bonetto - vinicius.bonetto@ hotmail.com

Universidade Federal do Paraná

Vinicius Rogel - vini.rogel@gmail.com

Universidade Federal do Paraná

Fernando Armani - fernando.armani@ufpr.br

Universidade Federal do Paraná

Cesar Aparecido da Silva - cesar.silva@ufpr.br

Universidade Federal do Paraná 


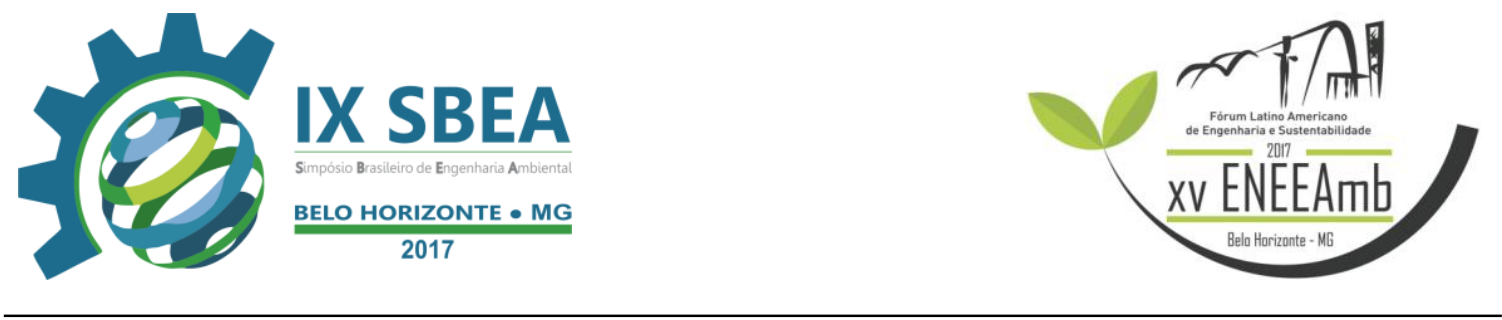

\section{RESUMO}

O objetivo deste trabalho foi investigar a importância atribuída por estudantes do ensino médio ao ensino superior, e relacionar com a qualidade do ensino médio e se os mesmos conheciam o curso de Engenharia Ambiental e Sanitária ofertado pela universidade presente no município. Foram avaliados 50 estudantes de escola pública do terceiro ano do ensino médio da cidade de Pontal do Paraná, localizado no litoral paranaense. Os resultados apontaram que $88 \%$ dos estudantes têm interesse em cursar um ensino superior após a conclusão do ensino médio, porém muitos desses não realizaram vestibular ou Enem. Alguns também não sabiam da existência da universidade federal pública na cidade e dos cursos ofertados. Os resultados indicam que em Pontal do Paraná, os estudantes do ensino médio de escola pública em sua maioria não estão preparados para ingressar no Ensino Superior.

Palavras-chave: escola pública, educação superior, vestibular, Enem

\section{INTRODUÇÃO/OBJETIVO}

Este trabalho surgiu como resultado de um questionamento sobre o interesse de jovens do Litoral Paranaense sobre cursar o ensino superior e identificar o que é a Engenharia Ambiental e Sanitária ofertada em Pontal do Paraná sob a ótica de estudantes do Ensino Médio de escola pública na região.

No meio acadêmico, o ensino médio é a etapa imediatamente anterior à graduação, por isso essa categoria de estudantes foi escolhida para os estudos deste trabalho, uma vez que nesta fase da vida existem questionamentos relacionados ao futuro e, geralmente, é neste momento que muitas pessoas decidem o que pretendem fazer em sua vida. No ensino médio, conhecimento e trabalho se confundem e é aí que se reconhece a relação entre ambos (RAMOS, 2011).

No Brasil, segundo dados do Observatório do PNE, que estão disponíveis online em site oficial, em 2001, 41,2\% dos jovens de 15 a 17 anos estavam regularmente matriculados no Ensino Médio, e em 2014, 61,4\%. Isso significa um aumento de 20,2\% dos jovens matriculados, o que é um crescimento considerável. No Paraná, em 2001, 50\% de jovens na mesma faixa etária estavam matriculados e, em 2014, 63,3\%. 


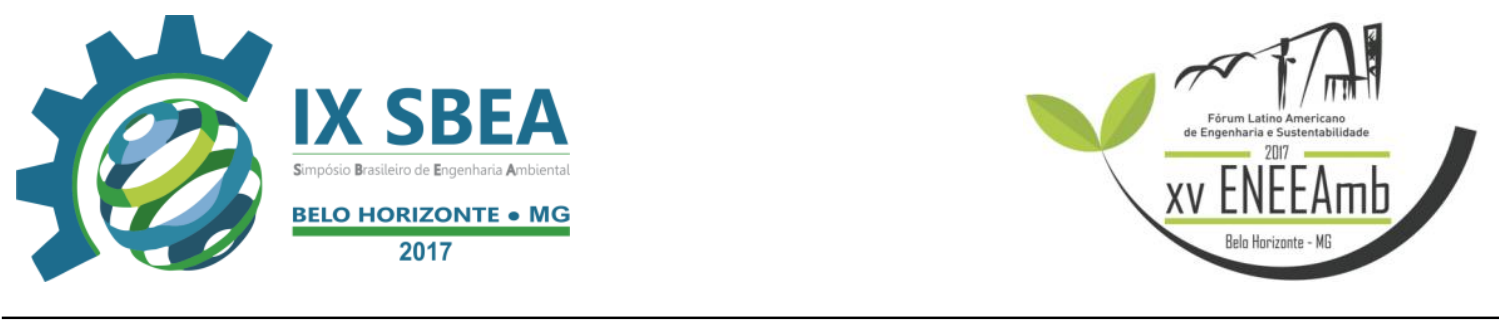

Porém, nem sempre o aumento do número de matrículas no Ensino Médio representa o aumento da qualidade do ensino do mesmo. Apesar da educação básica estar cada vez mais acessível à população, existe um antagonismo entre a quantidade de vagas disponíveis e a qualidade do ensino, principalmente por conta de questões políticoeconômicas, que sufocam os investimentos em educação no país, como afirmou Romualdo Oliveira (2007).

A qualidade do ensino médio reflete diretamente na perspectiva dos alunos com relação à continuidade de seus estudos através de um curso de graduação, e é essa perspectiva que este trabalho teve o objetivo de conhecer, relacionando-a com a qualidade do ensino médio que tem sido ofertado em nossa região. O conhecimento a respeito da existência de universidade pública, especialmente a UFPR, na região e entendimento sobre o curso de Engenharia Ambiental e Sanitária (EAS) também foram questionados.

\section{METODOLOGIA}

Este trabalho vem sendo aplicado nas escolas do litoral do Paraná, através do projeto de extensão universitária da Universidade Federal do Paraná denominado por Engenharia Ambiental e Sanitária nas Escolas, e gerenciado por professores do Curso de Engenharia Ambiental e Sanitária. Neste projeto, tem-se como intuito despertar o interesse dos alunos no ensino superior e também esclarecer questões relativas à educação ambiental.

O presente estudo foi realizado com estudantes do terceiro ano do ensino médio do Colégio Estadual Maria Helena Teixeira Luciano, localizado no balneário Shangri-lá, na cidade de Pontal do Paraná, litoral paranaense, após obter o consentimento da diretoria do colégio e dos professores.

Foi aplicado um questionário para os estudantes contendo as seguintes questões objetivas: 1) "Pretende fazer um curso superior após a conclusão do terceiro ano?" 2) “Fez o Exame Nacional do Ensino Médio (Enem) em 2016?” 3) “Conhece a UFPR no litoral paranaense?" 4) “Se sim, quais dos campi você conhece?" 5) "Sabe da existência dos cursos ofertados em Pontal do Paraná? Quais deles?" 6) "Tem interesse na área ambiental em geral?”. E uma questão discursiva: “O que você entende por Engenharia Ambiental e Sanitária?”. 


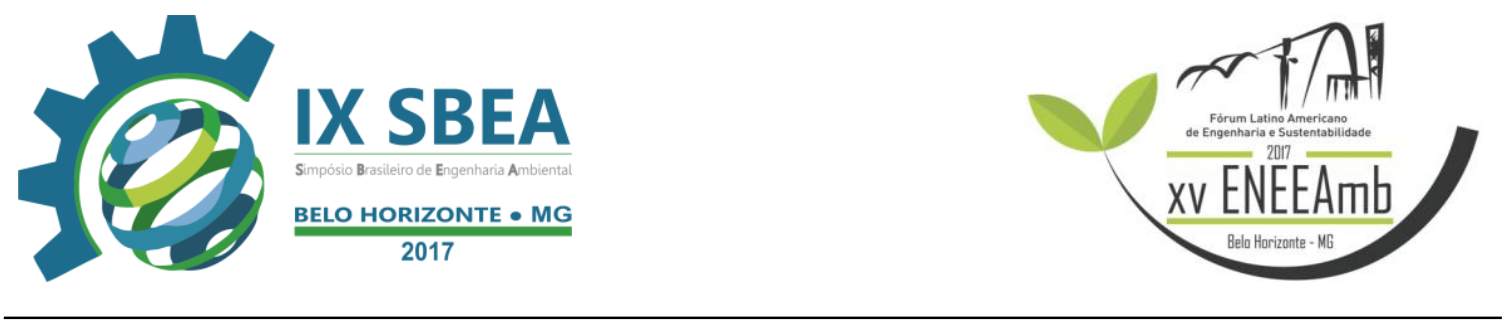

Os questionários foram aplicados em sala de aula com todos os estudantes presentes respondendo as questões ao mesmo tempo, com a supervisão dos aplicadores e dos professores, não foram dados grandes esclarecimentos a respeito das questões antes da aplicação, para que as respostas não sofressem nenhum tipo de influência. Os questionários foram recolhidos ao mesmo tempo e depois analisados.

Além dos questionários, também foram observados o comportamento dos alunos e dos professores frente ao tema em questão, sendo que todas as atitudes durante o período de aplicação do questionário foram avaliadas.

Após o dia da aplicação do questionário, retornou-se ao colégio para ministrar palestra sobre educação ambiental, cujo foco era o litoral do Paraná e suas problemáticas ambientais. Enfatizou-se o papel da universidade para sanar essas questões e a importância do aluno residente de Pontal do Paraná ingressar na Universidade para atuar como protagonista neste trabalho. Na sequência, foram esclarecidas as dúvidas que os alunos tiveram na aplicação dos questionários. Também complementando com informações sobre a UFPR e seus campis, citando os cursos oferecidos no litoral, em especial a Engenharia Ambiental e Sanitária.

\section{RESULTADOS E DISCUSSÃO}

No total, 50 estudantes do terceiro ano do ensino médio participaram da pesquisa, destes, $88 \%$ disseram ter interesse em fazer um curso superior, $10 \%$ responderam talvez e $2 \%$ não tem interesse.

Com relação ao Exame Nacional do Ensino Médio (Enem), 72\% fizeram o exame e $28 \%$ não. Dos estudantes que disseram ter interesse em cursar uma graduação $75 \%$ fizeram a prova do Enem.

Sobre a UFPR no Litoral Paranaense, $86 \%$ relataram que conhecem pelo menos um dos campi. O campus do Setor Litoral em Matinhos, é conhecido por $70 \%$ dos estudantes, Pontal do Sul por $46 \%$ e o Campus Mirassol por $28 \%$. 14\% não sabia da existência da UFPR no litoral.

Dos cursos ofertados em Pontal do Paraná, 46\% estudantes conhece o curso de Engenharia Ambiental e Sanitária, 62\% conhece o curso de Engenharia Civil, 26\% 


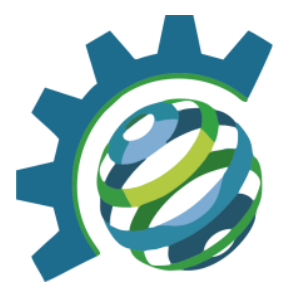

conhecem Engenharia de Aquicultura, 66\% conhecem o curso de Ciências Exatas e 70\% conhece Oceanografia.

$14 \%$ do total possui interesse com certeza na área ambiental em geral, $20 \%$ tem interesse, mas com dúvidas, $12 \%$ talvez, $32 \%$ nem tanto, mas quem sabe e $22 \%$ não, nem um pouco.

As questões discursivas foram separadas em duas categorias: Os que acertaram totalmente ou em partes, têm algum conhecimento do assunto, os que erraram ou deixaram em branco, não têm conhecimento sobre a Engenharia Ambiental e Sanitária. Do total, $76 \%$ não possui interesse sobre a área e $24 \%$ tem algum conhecimento.

Baseado nos resultados encontrados, sugere-se que a maioria dos estudantes que responderam o questionário possuem interesse em realizar um curso superior. Porém, um quarto dos interessados não realizaram o ENEM. Interessante ressaltar que ao serem questionados oralmente, a grande maioria dos estudantes, assim como constatado no questionário afirmou ter interesse no ensino superior, o que deixou os próprios professores, que convivem com eles diariamente, surpreendidos. Os professores alegaram que, apesar do grande número de interessados, a maioria se quer se inscreveu no processo de seleção, o vestibular, para atingir esse objetivo.

A maioria dos estudantes conhecem pelo menos uma das unidades da Universidade Federal do Paraná (UFPR) no litoral, sendo entre eles o campus de Matinhos o mais conhecido, seguido por Pontal do Sul e por último o da unidade de Mirassol. O campus UFPR Litoral, localizado em Matinhos é provavelmente o mais conhecido por esses alunos devido ao fato de possuir uma melhor infraestrutura, maior número de cursos ofertados, e também porque estudantes deste campus já realizaram estudos parecidos com os mesmos alunos em 2015.

De acordo com os dados coletados, 54\% não tem interesse na área ambiental, $12 \%$ não tem certeza e $34 \%$ possui interesse. Desta forma, existe uma quantidade considerável de alunos que poderiam vir a ser estudantes do curso de EAS.

A respeito do conhecimento sobre Engenharia Ambiental e Sanitária, como a grande maioria (76\%) não possui conhecimento sobre a área, é necessário dar um maior esclarecimento e informações sobre o mesmo, que pode ser realizado através de ciclo de 


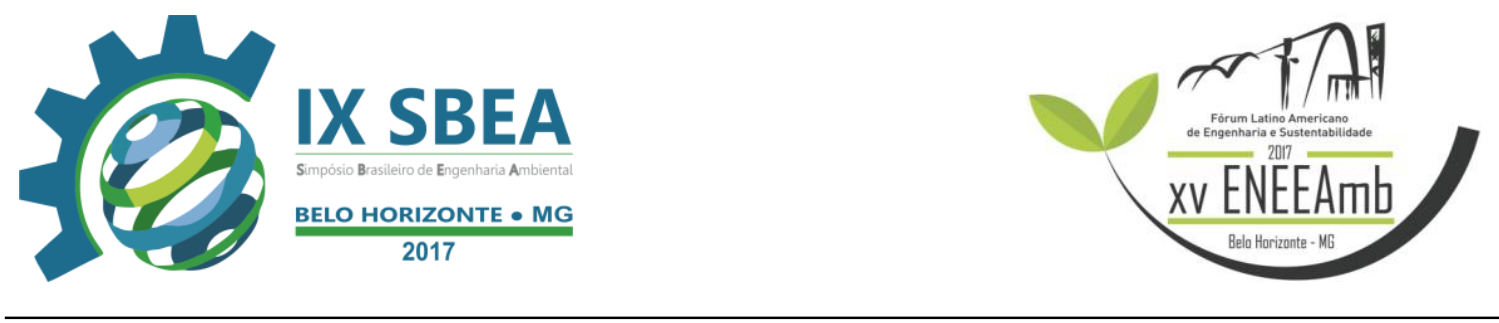

palestras, entre outras iniciativas. Contudo, os outros $24 \%$ que demonstraram conhecimento observou-se que ainda faltam alguns esclarecimentos, principalmente, na área sanitária. Por exemplo, algo que chamou atenção foi que a palavra "comércio" apareceu várias vezes nas questões discursivas, mostrando que os alunos relacionaram o nome "sanitária" com comércio, confundindo com a vigilância sanitária.

As observações realizadas com relação ao comportamento dos estudantes durante a visita dos pesquisadores, foi de que esses formandos do colegial estão despreparados para uma vida universitária, demonstrando grande imaturidade em quase todo o momento com relação ao entendimento do assunto proposto. Muitas vezes foi difícil manter a atenção desses para a apresentação, muitos faziam brincadeiras não convenientes ao momento, o que fez com que os aplicadores refletissem de como deve ser a relação do professor e aluno.

\section{CONCLUSÕES/RECOMENDAÇÕES}

Com base nas avaliações obtidas, é possível afirmar que a maioria dos estudantes do terceiro ano do ensino médio do colégio Maria Helena possui interesse em realizar um curso superior, porém, a falta de informação e o não esclarecimento sobre os cursos ofertados pela UFPR no litoral paranaense, principalmente em Pontal do Paraná, faz com que os alunos tenham dificuldades na hora de escolher uma carreira profissional.

Assim, sugere-se a intervenção do poder público, como ações como os de projetos de extensão para levar as informações necessárias sobre o ensino superior, e sobre o Curso de Engenharia Ambiental e Sanitária para despertar nos estudantes o interesse em se tornar engenheiros que possam ajudar a resolver questões de máxima importância sobre a saúde ambiental que tem assolado o litoral paranaense, tais como problemas de drenagem, resíduos e questões epidemiológicas como a dengue, entre outros.

Sugere-se ainda que esse trabalho seja replicado em outras escolas para auxiliar os estudantes do litoral paranaense na escolha do seu futuro curso superior.

\section{REFERÊNCIAS BIBLIOGRÁFICAS}




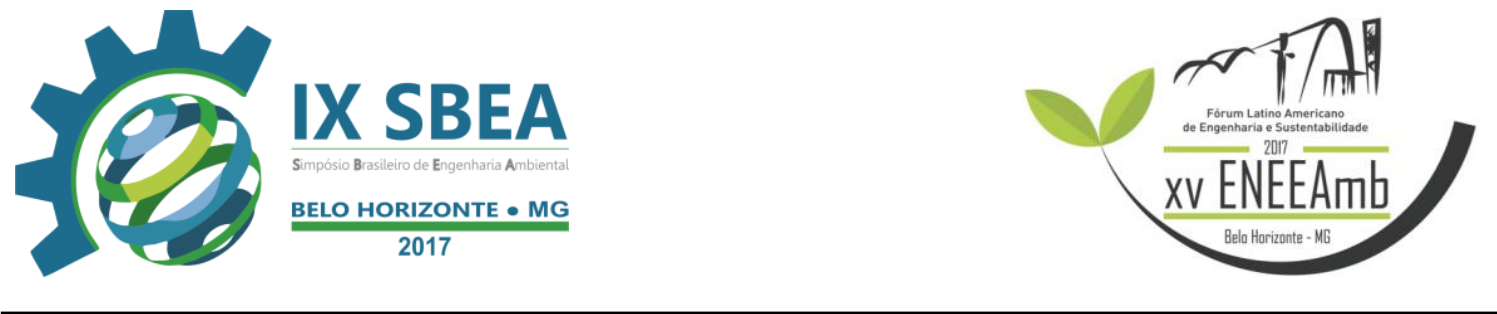

DARIDO, S. C., GALVÃO, Z., FERREIRA, L. A., FIORIN, G. Educação Física no Ensino Médio: Reflexões e Ações. MOTRIZ - Volume 5, Número 2, Dezembro/1999

Observatório do PNE. Ensino Médio: Porcentagem de jovens de 15 a 17 anos Matriculados no Ensino Médio. 2015. Disponível em <http://www.observatoriodopne.org.br/metas-pne/3ensino-medio/indicadores>. Acesso em 16 de junho de 2016.

OLIVEIRA, R. P. Da universalização do ensino fundamental ao desafio da qualidade: uma análise histórica. Educ. Soc., Campinas, vol. 28, n. 100 - Especial, p. 661-690, out. 2007.

RAMOS, M. N. Currículo para o ensino médio em duas diferentes modalidades: Concepções, propostas e problemas. Educ. Soc, v. 32, n. 116, p. 771-788, 2011.

SPARTA, M., GOMES, W. B. Importância Atribuída ao Ingresso na Educação Superior por Alunos do Ensino Médio. Revista Brasileira de Orientação Profissional, 2005, 6 (2), pp. 45 - 53 